\title{
Effect of Initiation of Basal Insulin Glargine on Glycemic Control in Patients with Diabetes: Real Life Experience from Hong Kong
}

\author{
Chi-Kin Yeung1 ${ }^{*}$, Fhkcp Fhkam¹, Wilson Wai-man Ngai', Ip-tim Lau1 \\ ${ }^{1}$ Department of Medicine, Tseung Kwan O Hospital, Hong Kong, China \\ ${ }^{2}$ Sanofi (Hong Kong) Ltd., Hong Kong, China \\ Email: *yeungck@ha.org.hk
}

How to cite this paper: Yeung, C.-K., Fhkam, F., Ngai, W.W.M. and Lau, I.-T. (2017) Effect of Initiation of Basal Insulin Glargine on Glycemic Control in Patients with Diabetes: Real Life Experience from Hong Kong. Journal of Diabetes Mellitus, 7, 108-120.

https://doi.org/10.4236/jdm.2017.73009

Received: June 29, 2017

Accepted: July 25, 2017

Published: July 28, 2017

Copyright (ㅇ 2017 by authors and Scientific Research Publishing Inc. This work is licensed under the Creative Commons Attribution International License (CC BY 4.0).

http://creativecommons.org/licenses/by/4.0/

\begin{abstract}
Introduction: To assess the changes in glycemic control after initiating or switching to a basal insulin analogue in patients with diabetes mellitus. Methods: A retrospective, observational analysis was conducted using electronic data from a Hong Kong regional hospital. Data from adult patients with type 1 and 2 diabetes mellitus (T1DM and T2DM, respectively) who had been prescribed with basal insulin glargine in 2008-2010, with recorded HbAlc levels at the time of initiation, at 6 and 12 months thereafter, were analysed. Results: Data from 106 eligible patients were analysed. Substantial reduction in HbAlc and fasting sugar levels were reported in both $\mathrm{T} 1 \mathrm{DM}(\triangle \mathrm{HbA1c}=1.5 \%, \Delta$ $\mathrm{FBG}=1.3 \mathrm{mmol} / \mathrm{L} \mathrm{p}<0.05)$ and T2DM $(\Delta \mathrm{HbA} 1 \mathrm{c}=1.2 \%, \Delta \mathrm{FBG}=2.9$ $\mathrm{mmol} / \mathrm{L} \mathrm{p}<0.05)$ patients after 12 months of therapy. A total of $42 \%$ of T1DM and $26 \%$ of T2DM patients achieved HbAlc levels $<7.0 \%$. After adjustment, T2DM patients who were insulin naive achieved a statistically greater HbAlc reduction $(\Delta=1.7 \%)$ than those who previous treated with premixed or basal bolus insulin $(\Delta=0.3 \%)(\mathrm{p}<0.05)$. Percentage of patients experiencing hypoglycaemia reduced from $69 \%$ to $62 \%$ in T1DM but increased from $26 \%$ to $36 \%$ in T2DM patients. All hypoglycaemic episodes recorded were either asymptomatic or mild and self-limiting. Only $4 \%$ of the patients discontinued treatment at the end of 12 months. Conclusions: In real life clinical practice, a single daily basal insulin analogue therapy provided effective glycemic control with an acceptable risk of mild hypoglycaemia.
\end{abstract}

\section{Keywords}

Glycemic Control, Insulin Initiation, Insulin Glargine, Type 1 Diabetes Mellitus, Type 2 Diabetes Mellitus, Hong Kong 


\section{Introduction}

With an estimation of $60 \%$ of the world's diabetic population living in Asia [1], diabetes has a significant impact not only on mortality [2], but also on morbidity [2], treatment cost [3] and quality of life [4] in this region. Since the first reports on the epidemiology of diabetes were published in Hong Kong in the early 1990s [5], the prevalence of diabetes mellitus has been increasing steadily from $4.5 \%$ in 1990 to $10 \%$ recently [6]. Currently, it is estimated that $10 \%-12 \%$ of the adult population in Hong Kong are suffering from type 2 diabetes mellitus (T2DM) [7] and the age of onset in type 1 diabetes mellitus (T1DM) is getting lower [8].

The main focus of antidiabetic therapy is to achieve and maintain glycemic control in order to slow disease progression and prevent diabetic complications together with no or minimal hypoglycaemia [9] [10]. Insulin therapy may be initiated as a supplement or as a replacement in patients with uncontrolled diabetes [11]. For most of the patients, starting with once daily intermediate- or long-acting basal insulin is a readily acceptable and practical method. The goal of basal insulin is to suppress hepatic glucose production and improve fasting hyperglycaemia [12]. Clinical trials have showed that the use of the long acting insulin analogues enables diabetic patients to reach glycemic targets with a low risk of hypoglycaemia [13].

Insulin glargine (Lantus ${ }^{\circledast}$ ) is the a long-acting basal insulin that is indicated for the treatment of diabetes mellitus in adults, adolescents and children aged 2 years and above. It was shown to be as effective as other commonly used basal insulins-Neutral Protamine Hagedorn (NPH) insulin [14] and Detemir [15]. Despite the plethora of evidence from various randomised clinical trials confirming the benefits of basal insulin analogue therapy in the management of diabetes, the extent to which these results translates in real life clinical practice is unclear [16] [17]. Several observational studies have attempted to address this issue but those studies were conducted in the Caucasian population [18] [19]. In this retrospective analysis, we aim to assess the effects of initiating a basal insulin analogue on glycemic control in type 1 and 2 diabetes patients in a local clinical setting in Hong Kong. Specifically, we intend to determine the effect of such therapy on $\mathrm{HbAlc}$ control and other therapeutic and safety parameters-FBG, weight gain, insulin dosage and hypoglycaemia.

\section{Materials and Methods}

\subsection{Study Design}

This was a retrospective case series review.

\subsection{Eligibility Criteria and Data Evaluation}

Patients with T1DM or T2DM, aged $\geq 21$ years, who had been prescribed basal insulin glargine, either as a supplementary insulin or as a part of basal-plus regimen, in Jan 2008-Dec 2010 at Tseung Kwan O Hospital (a regional hospital in Hong Kong) were included. Their baseline HbAlc and other pertinent data 
(FBG, weight, insulin dose and incidence of hypoglycaemia) at the time of initiation of insulin glargine and at 6 and 12 months thereafter, were collected through electronic health records system.

The principal analysis was to evaluate the change in HbA1c over a 6 and 12month period after glargine initiation. Secondary analysis included change in fasting blood glucose (FBG), body weight (kg), incidence of hypoglycaemia, and daily insulin dose (IU) at 6 and 12-month. Information on associated comorbidities including hypertension, coronary artery disease, myocardial infarction, PCI/CABG, heart failure, stroke, peripheral vascular disease, limp amputation, dyslipidaemia, dialysis/transplant, and obesity was also extracted.

The point-of-care testing reading less than $4 \mathrm{mmol} / \mathrm{l}$ with compatible symptom(s) was considered to have hypoglycemia. Those episodes requiring third party assistance were defined as severe hypoglycemia. The frequency and severity of hypoglycemic episodes were expeditely reviewed in the electronic health records.

\subsection{Patient Disposition}

A total of 120 adult patients had been prescribed with insulin glargine in 2008-2010. Of these, 106 patients had complete data at baseline and follow up visits after glargine treatment were included for analysis. Their insulin glargine therapies were initiated in the period of January 2002 to February 2010. Patient's electronic health records from January 2002 to March 2011 were subsequently reviewed.

\subsection{Statistical Analysis}

All data recorded were analysed in an explorative manner. Missing HbAlc data was imputed when patients had at least baseline and 6 months measurements during the 12 month period. The mean change during the 12 months following the switch was calculated. Continuous variables were presented as frequency, mean, median and standard deviation while categorical variables were described by the frequencies of each modality. The change in HbAlc and FBG from baseline to 6 months and from baseline to 12 months was estimated and adjusted by repeated measure ANOVA (analysis of variance). Linear mixed effect model was applied to assess whether there is any fixed effects of 1) disease duration, and 2) prior regimen on the change in $\mathrm{HbAlc}$ level. The data was adjusted for repeated measure per patient over time with change in $\mathrm{HbA1C}$ relative to time of insulin initiation as the dependent variable. The fixed effects for assessment of disease duration are baseline $\mathrm{HbA1C}$ value, disease duration, the time since insulin initiation as a categorical variable, and the interaction between disease duration and the time since insulin initiation. The fixed effects for assessment of prior regimen type are baseline $\mathrm{HbA} 1 \mathrm{C}$ value, prior regimen type, the time since insulin initiation as a categorical variable, and the interaction between prior regimen type and the time since insulin initiation. All statistical analyses were performed at $5 \%$ significance using 2 -sided tests or confidence intervals. Statistical analysis 
was performed using the SPSS software version 14 (IBM, New York, USA).

\section{Results}

\subsection{Baseline Characteristics}

About three-quarters of the patients $(75.5 \%, \mathrm{n}=80)$ had T2DM, while onequarter of the patients $(24.5 \%, \mathrm{n}=26)$ had T1DM. The mean age of the patients with T1DM was 36.5 years and that of T2DM patients was 61.1 years. Mean $\mathrm{HbA1c}$ at baseline before switching was similar in each group $(9.1 \%$ and $9.0 \%$ respectively). Mean duration of diabetes in patients at the time of recording was 14.6 years for T1DM and 16.7 years for T2DM. Patients with T2DM had a greater number of comorbidities than those with T1DM patients (2.2 versus 0.9). Nearly $80 \%$ of patients have hypertension and dyslipidaemia while $15 \%$ of the patients have coronary artery disease. $95 \%$ of T2DM patients were already put on oral antidiabetic (OAD) agents with $90.0 \%, 83.8 \%, 20.0 \%$ and $18.8 \%$ on metformin, sulfonylurea, glitazone, DPP4 inhibitors respectively. The proportion of patients reporting prior hypoglycaemia was higher in T1DM (69.2\%) than in T2DM patients (26.3\%) (Table 1).

In T1DM patients, the primary reason of switching to glargine was to reduce the incidence of hypoglycaemia (reported in $50 \%$ of the patients) while, in T2DM patients, the main reason was to improve glycemic level (reported in $81 \%$ of the patients) (Table 1).

\subsection{Glycaemic Control}

After 12 months on insulin glargine, the mean HbAlc levels dropped significantly by $1.5 \%$ (from $9.1 \% \pm 2.3 \%$ to $7.6 \% \pm 1.3 \%, \mathrm{p}<0.05$ ) in T1DM patients and by $1.2 \%$ (from $9.0 \% \pm 1.5 \%$ to $7.8 \% \pm 1.4 \%, \mathrm{p}<0.05$ ) in T2DM patients (Figure 1). When mean baseline HbAlc level $(\geq 7.0 \%-7.9 \%, \geq 8.0 \%-8.9 \%$, $\geq 9.0 \%-9.9 \%$ and $\geq 10.0 \%$ ) was listed against the improvement in HbAlc after switching, patients with $\mathrm{HbAlc} \geq 10.0 \%$ had a greater numerical reduction in mean $\mathrm{HbA1c}$ ( $\Delta$ for $\mathrm{T} 1 \mathrm{DM}=3.8 \%$; $\Delta$ for $\mathrm{T} 2 \mathrm{DM}=2.3 \%$ ) while patients with $\mathrm{HbA} 1 \mathrm{c}<8.0 \%$ had a smaller improvement $(\Delta$ for $\mathrm{T} 1 \mathrm{DM}=0.3 \%$; $\Delta$ for $\mathrm{T} 2 \mathrm{DM}=$ $0.3 \%)$ [Not shown].

In addition, T2DM who had a short disease duration $(<5$ years of diabetes) had a greater reduction in HbAlc numerically $((\Delta=1.8 \%, \mathrm{p}<0.05)$ than those with long disease duration $(6-10$ years: $\Delta=1.2 \%, \mathrm{p}<0.05$ and $>10$ years: $\Delta=$ $1.0 \%, \mathrm{p}<0.05$ ) (Figure 2). The change in HbA1c between the subgroups of different disease duration, however, did not reach statistical significance $(\mathrm{p}>0.05)$. On the other hand, T2DM patients who were insulin naïve achieved a statistically greater $\mathrm{HbA1c}$ reduction $(\Delta=1.7 \%)$ than those who previously used basal bolus or premixed basal insulin $(\Delta=0.3 \%)$ at 12 months after the switch (Figure 3 ). The proportion of patients achieving $\mathrm{HbAlc}<7.0 \%$ after 12 months of initiating glargine was $42 \%(\mathrm{n}=11)$ in T1DM and 26\% $(\mathrm{n}=21)$ in T2DM [Not shown]. 
Table 1. Baseline characteristics of enrolled diabetic patients.

\begin{tabular}{|c|c|c|}
\hline & $\mathrm{T}^{1 D \mathrm{DM}^{1}}$ & $\mathrm{~T} 2 \mathrm{DM}^{2}$ \\
\hline Baseline characteristics & $\mathrm{N}=26$ & $\mathrm{~N}=80$ \\
\hline Males, N (\%) & $11(42.3)$ & $37(46.3)$ \\
\hline Age (years), mean (SD) & $36.5(13.3)$ & $61.1(10.9)$ \\
\hline Weight (kg), mean (SD) & $61.8(15.9)$ & $63.3(16.7)$ \\
\hline Hb1Ac (\%), mean (SD) & $9.1(2.3)$ & $9.0(1.5)$ \\
\hline Duration of diabetes (years), mean (SD) & $14.6(9.3)$ & $16.7(7.8)$ \\
\hline Number of comorbidities, mean (SD) & $0.9(1.0)$ & $2.2(1.3)$ \\
\hline \multicolumn{3}{|l|}{$\mathrm{N}(\%)$} \\
\hline Hypertension & $8(30.8)$ & $63(78.8)$ \\
\hline Coronary Artery Disease & $2(7.7)$ & $12(15.0)$ \\
\hline Myocardial Infarction & $1(3.8)$ & $2(2.5)$ \\
\hline Congestive Heart Failure & $0(0.0)$ & $3(3.8)$ \\
\hline Stroke & $1(3.8)$ & $6(7.5)$ \\
\hline Peripheral Vascular Disease & $0(0.0)$ & $2(2.5)$ \\
\hline Dyslipidaemia & $12(46.2)$ & $65(81.3)$ \\
\hline Renal Impairment & $0(0.0)$ & $11(13.8)$ \\
\hline $\mathrm{PCI} / \mathrm{CABG}$ & $0(0.0)$ & $9(11.3)$ \\
\hline Limp amputation & $0(0.0)$ & $1(1.3)$ \\
\hline Dialysis/transplant, & $0(0.0)$ & $1(1.3)$ \\
\hline $\mathrm{OAD}^{3} \mathrm{~s}$ prescribed prior to commencing insulin, mean (SD) & $0.1(0.4)$ & $2.2(0.9)$ \\
\hline Patients reporting prior hypoglycaemia, N (\%) & $18(69.2)$ & $21(26.3)$ \\
\hline Prior treatment regimens, $\mathrm{N}(\%)$ & $\mathrm{N}=26$ & $\mathrm{~N}=80$ \\
\hline Insulin naïve & $5(19.2)$ & $48(60.0)$ \\
\hline $\mathrm{OAD}$ & $2(7.7)$ & $76(95.0)$ \\
\hline $\mathrm{NPH}^{4}$ & $3(11.5)$ & $17(21.3)$ \\
\hline Basal bolus & $16(61.5)$ & $7(8.8)$ \\
\hline Premixed & $3(11.5)$ & $8(10.0)$ \\
\hline Reasons to switch to glargine, $\mathrm{N}(\%)$ & $\mathrm{N}=26$ & $\mathrm{~N}=80$ \\
\hline Hypoglycaemia & $13(50.0)$ & $14(17.5)$ \\
\hline Uncontrolled $\mathrm{HbAl} \mathrm{c}^{5}$ & $12(46.2)$ & $65(81.3)$ \\
\hline Convenience & $1(3.8)$ & $0(-)$ \\
\hline Others & $0(-)$ & $1(0.0)$ \\
\hline
\end{tabular}

${ }^{1}$ Type 1 diabetes mellitus. ${ }^{2}$ Type 2 diabetes mellitus. ${ }^{3}$ Oral antidiabetic. ${ }^{4}$ Neutral Protamine Hagedorn. ${ }^{5}$ Glycosylated haemoglobin.

\subsection{Overall Change in FBG}

Within 12 months of initiation with insulin glargine, the mean FBG dropped from $11.1 \pm 4.2 \mathrm{mmol} / \mathrm{L}$ at baseline to $9.7 \pm 4.9 \mathrm{mmol} / \mathrm{L}$ in T1DM patients [Not shown]. In T2DM patients, the mean FBG reduced from $10.1 \pm 3.3 \mathrm{mmol} / \mathrm{L}$ to $7.2 \pm 3.3 \mathrm{mmol} / \mathrm{L}$. The reduction in FBG was statistically significant in T2DM patients $(\mathrm{p}<0.05)$ but not in T1DM patients. 


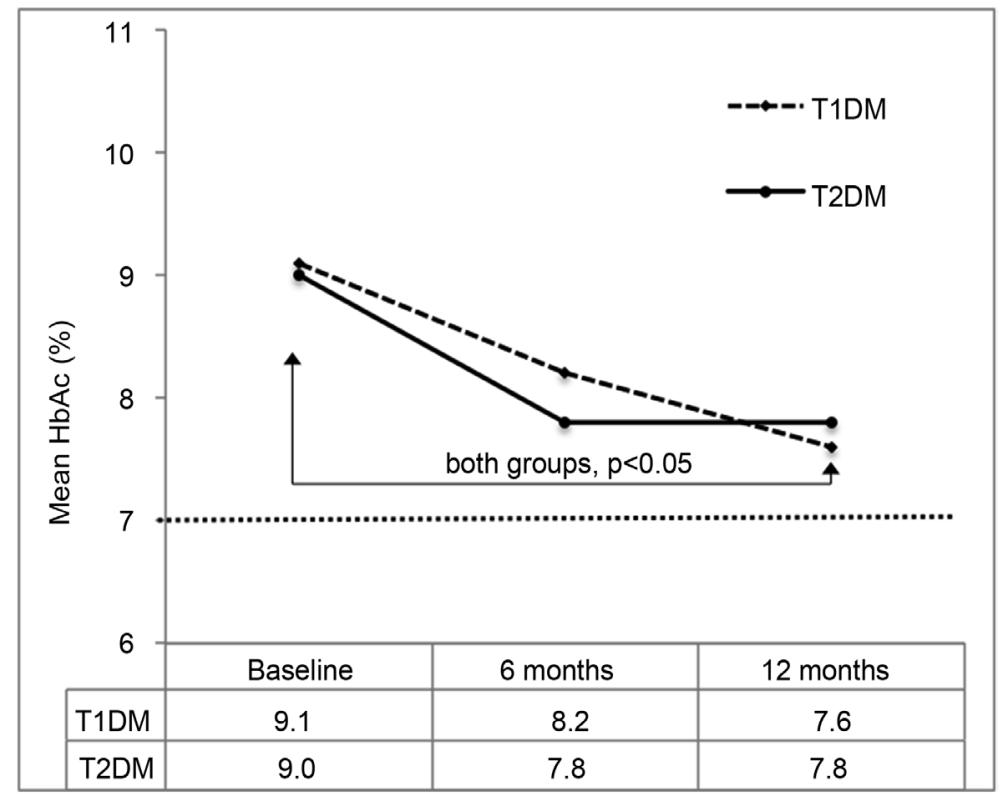

Figure 1. Overall change in HbA1c levels in T1DM and T2DM patients after initiation of glargine. HbAlc.

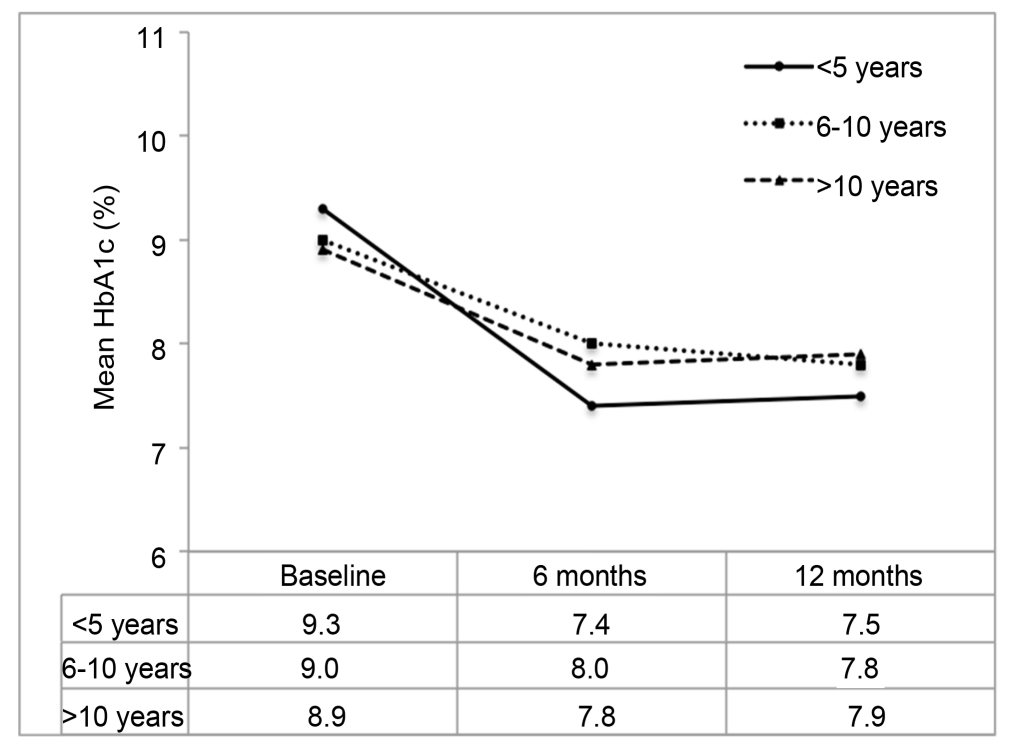

Figure 2. Reduction in HbA1c in T2DM patients based on duration of diabetes prior to initiation of glargine. Abbreviations: T2DM-type 2 diabetes mellitus.

\subsection{Insulin Dose and Body Weight Change}

The total daily dose of insulin glargine remained the same at 18.8 IU in T1DM patients $(0.33 \mathrm{IU} / \mathrm{kg}$ at 6 months and 12 months) but increased slightly from 19.2 IU at 6 months to $20.3 \mathrm{IU}$ at 12 months in T2DM $(0.30 \mathrm{IU} / \mathrm{kg}$ and 0.32 $\mathrm{IU} / \mathrm{kg}$ at 6 months and 12 months respectively).

There was no significant change in weight in T1DM (mean body weight of $61.8 \pm 15.9 \mathrm{~kg}$ at baseline and $61.8 \pm 10.8 \mathrm{~kg}$ after 12 months of treatment with insulin glargine). In T2DM patients, mean body weight increased slightly from 


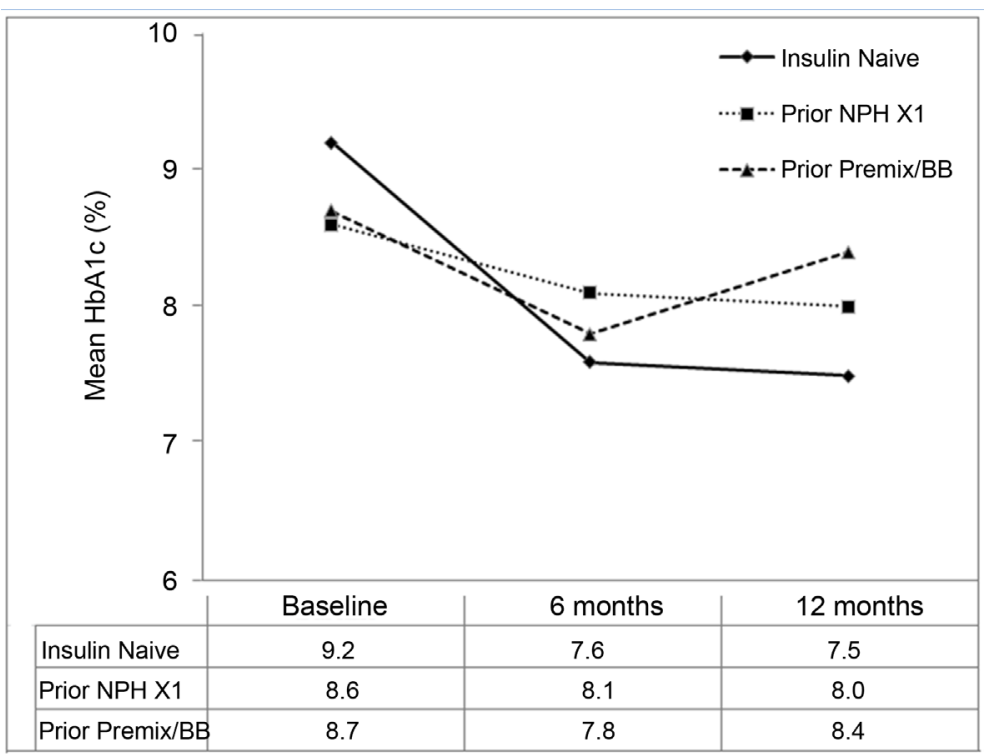

Figure 3. Reduction in $\mathrm{HbA1c}$ in insulin naive T2DM patients and previous T2DM Insulin users. Abbreviations: BB-Basal Bolus Regimen.

$64.9 \pm 13.4 \mathrm{~kg}$ to $66.7 \pm 10.8 \mathrm{~kg}$ but this increase was not statistically significant.

\subsection{Hypoglycaemia and Discontinuation}

At baseline, $69 \%$ of T1DM and 26\% of T2DM experienced hypoglycaemia. After 12 months of using insulin glargine, the percentage of T1DM patients who experienced hypoglycaemia deceased to $62 \%$ while the percentage of T2DM patients who experienced hypoglycaemia increased to $36 \%$ (Figure 4). The increase in rate of hypoglycaemia in T2DM was observed mainly in insulin naive patients. In fact, there was a decrease in hypoglycaemia in patients who had used once daily NPH or premixed/basal-bolus insulin at baseline. The percentage of T2DM patients who had used once daily NPH previously and experienced hypoglycaemia dropped from $47 \%$ at baseline to $0 \%$ over the 12 months following the switch while the percentage of patients who used premixed/basal bolus regimen previously and experienced hypoglycaemia dropped from $60 \%$ to $0 \%$ during the same time interval (Figure 5). All recorded episodes of hypoglycaemia were either asymptomatic or mild and self-limiting.

There were only four percent of patients $(n=3)$ having discontinued the insulin therapy within 12 months following its commencement.

\section{Discussion}

Insulin therapy is the mainstay of T1DM treatment and may be the ultimate therapy for a group of T2DM patients [11]. This retrospective, observational study showed that T1DM and T2DM patients who have been switched to glargine experienced a $\mathrm{HbAlc}$ reduction of $1.5 \%$ and $1.2 \%$ respectively within 12 months after the switch. The improvement was achieved without a significant increase in body weight or severe hypoglycaemia. These findings are in agreement with data from other observational studies in which patients were switched 


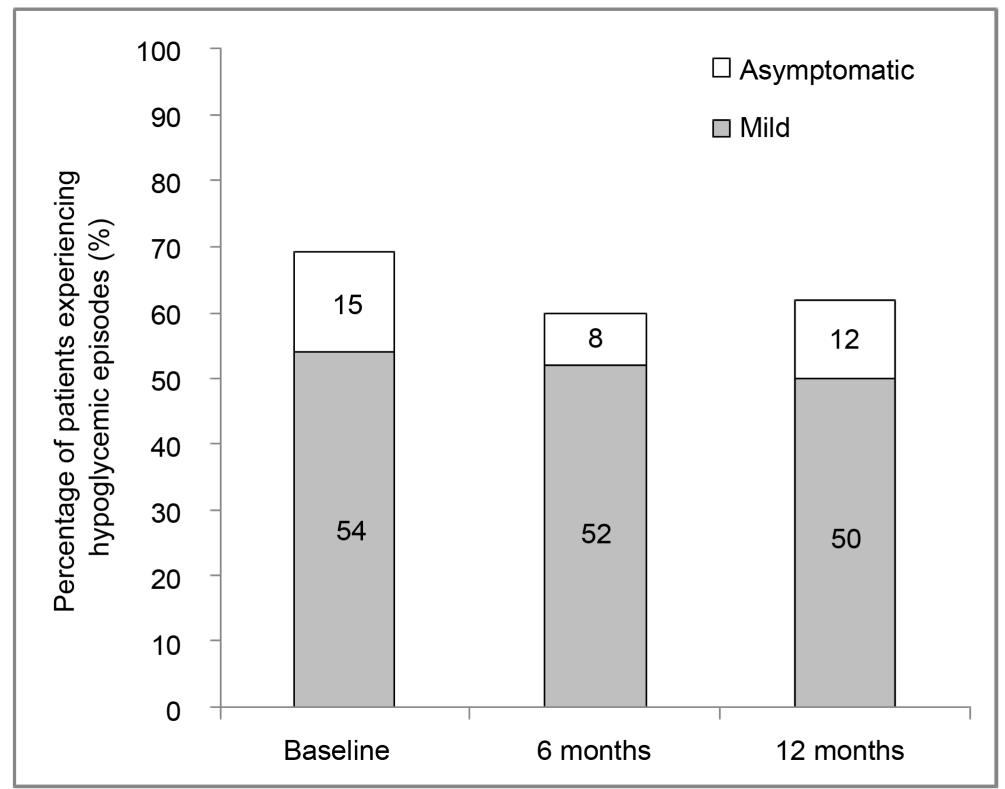

T1DM

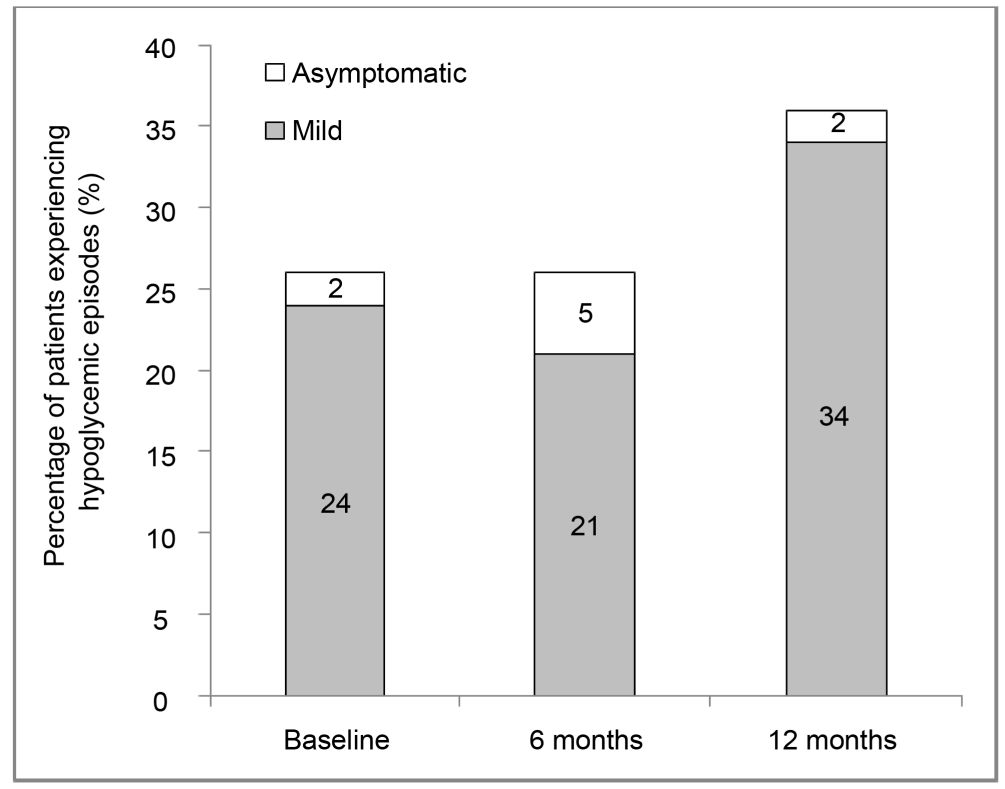

$\mathrm{T} 2 \mathrm{DM}$

Figure 4. Percentage of patients experiencing hypoglycemic episodes on insulin glargine at baseline, 6 months and one year.

to a glargine based regimen [16]-[21]. Our analysis demonstrated a relationship between baseline $\mathrm{HbAlc}$ values and the improvement in $\mathrm{HbA1c}$ levels. Patients with baseline HbAlc $>8 \%$ showed a reduction of $1.5 \%$, while those with $\mathrm{HbA} 1 \mathrm{c}>10 \%$ experienced a greater reduction of $2.8 \%$, suggesting even a single daily insulin injection could be effective when glycaemic control was exceptionally poor.

The optimal time for initiating insulin in T2DM patients, whether early or late till OAD failure, is still controversial but there are studies linking delayed insulin treatment with disease progression [22]. In real life clinical practice, however, 


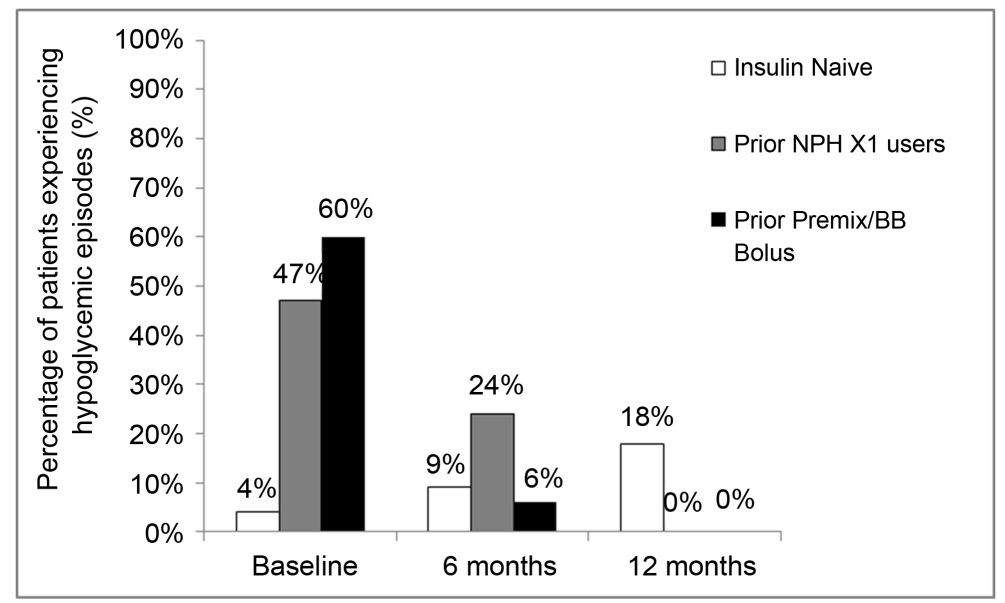

Figure 5. Percentage of patients experiencing hypoglycemic episodes on insulin glargine at baseline, 6 months and one year (by Type of Prior Therapy). Abbreviations: T1DM-type 1 diabetes mellitus, T2DM-type 2 diabetes mellitus, NPH-neutral protamine Hagedorn.

timely initiation of insulin was often hampered by concerns about weight gain, hypoglycaemia, and patient's fear of injections [23] [24]. In our study, $60 \%$ of T2DM patients (mean HbAlc: 9.0\%; mean duration of diabetes: 16.7 years) were insulin-naïve at baseline despite a prolonged disease duration. Our results demonstrated that T2DM patients with early disease ( $<5$ years of diabetes) at the time of initiation of glargine had a numerically greater improvement in HbAlc levels when compared to those with late stage disease ( $>10$ years of diabetes). Also, T2DM patients who were insulin naïve achieved a statistically greater HbAlc reduction $(\Delta=1.7 \%)$ than those who previously used basal bolus or premixed basal insulin $(\Delta=0.3 \%)$ at 12 months after the switch. Latest international consensus and clinical guidelines are shifting towards prompt insulinisation in order to achieve glycaemic control as early as possible [25] and our findings confirmed the benefits of this shift in a routine clinical practice.

Despite the improvement in $\mathrm{HbAlc}$ in our study, our analysis revealed less than half of T1DM and one-third of T2DM reached the HbAlc goal of less than 7\% within 12 months of glargine initiation. In comparison, the findings from the large-scale, multination International Diabetes Management Practice Survey showed a HbAlc target achievement of 25\% in T1DM patients and 35\% in T2DM patients [26] [27]. However, other studies assessing glycaemic control following basal insulin glargine in T2DM have reported higher rates of HbA1c target achievement [14] [28] [29]. One explanation for this subpar target achievement in our patients could be suboptimal insulin dosing. The FBG for T1DM patients after 12 months of glargine initiation was still at $9.7 \mathrm{mmol} / \mathrm{L}$ and the average glargine dose was only $0.34 \mathrm{IU} / \mathrm{kg}$, which means further up-titration could be done to optimise the FBG level. We, however, could not ascertain the reason behind the suboptimal dosing and can only speculate that care delivery limitation and fear of hypoglycaemia are contributing factors. Another possibility was the financial burden, as all the patients in this study paid for this insulin 
out of pocket as it was then not provided in the public health care setting where the study was conducted.

A major concern with regards to the use of insulin is the fear of hypoglycaemia. One of the advantages of insulin glargine over NPH is the reduced risk of hypoglycaemia in insulin-naïve patients as well as in patients who have previously treated with other insulins [20]. In our study, the primary reason for glargine initiation in T2DM patients was to improve glycaemic control while in T1DM patients; it was used to reduce the incidence of hypoglycaemia associated with previously used insulins. In the 12 months after initiation of or switch to insulin glargine, there was a notable decrease in the proportion of T1DM patients experiencing hypoglycaemia (from $69 \%$ to $62 \%$ ). On the other hand, the proportion of patients with type 2 diabetes who experienced hypoglycaemia increased to $36 \%$. Nonetheless, all the T2DM patients who experienced an increase in hypoglycaemia were patients who have not used insulin before (i.e. insulin naive patients) and basal insulin was known to increase the risk of hypoglycaemia [11]. For the other T2DM patients who were switched from other insulin formulations, there was a reduction in the proportion of patients who experienced hypoglycaemia after switching to glargine. This improvement in hypoglycaemia among patients who switched to a long acting basal insulin analogue from other insulin regimens (such as NPH or premixed/basal-bolus) has also been reported in other studies [14] [15] [30]. Most importantly, all hypoglycaemic episodes reported in our study were either asymptomatic or mild and selflimiting. .

The success of insulinization in attaining glycaemic control depends on adherence to the prescribed regimen [25]. Adherence to insulin therapy was reported to be inadequate [30] [31] and numerous factors related to patient and physician perceptions were thought to be responsible for treatment compliance [28]. In our study, a discontinuation rate was of only four percent at the end of 12 months following the initiation of insulin glargine. It indicated that once daily insulin injection is acceptable for most of all diabetic patients [32].

This is the first retrospective analysis on the real-life data of long acting insulin analogue in patients with diabetes in Hong Kong. However the analysis was associated with certain shortcomings. First, this retrospective observational study did not provide the same robust level of evidence as randomised controlled trials. Second, it was not designed to allow collection of all hypoglycaemic episodes. As a result, our hypoglycaemia rate might have been under-reported. Also, there were 3 cases where the 12 month HbAlc levels were missing. Extrapolation on that last data points were required. Since it involved only a minority of patients $(<2.8 \%)$, it would not affect the overall results of this study. Third, the decision to switch insulin treatment was not based on a standard treatment algorithm but instead on the clinical judgement of individual clinicians, thereby introducing bias in the selection of patients. Fourth, the analysis depended on the electronic medical records from a hospital, which did not record patient healthcare utilization outside the data capturing system. 
Despite these shortcomings, observational studies such as the current one are generally regarded as a better approach to assess the actual health outcomes of patients in routine care, more than randomised controlled trials [19] [20]. In our study, the decision to initiate long acting basal insulin analogue was based on the clinical judgment of the managing physicians and the results shed light on the effects of this kind of insulin preparations in the real life situation.

\section{Conclusion}

In conclusion, this observational study showed that, in T1DM and T2DM patients who have been treated with OADs or with other insulins with suboptimal efficacy or poor tolerability, long acting basal insulin analogue was effective in improving glycemic control with a reduced risk of hypoglycaemia in T1DM patients and T2DM patients switched from other insulins.

\section{References}

[1] Chan, J.C., Malik, V., Jia, W., Kadowaki, T., Yajnik. C.S., Yoon, K.H., et al. (2009) Diabetes in Asia: Epidemiology, Risk Factors, and Pathophysiology. The Journal of the American Medical Association, 301, 2129-2140.

https://doi.org/10.1001/jama.2009.726

[2] Unwin, N., Gan, D. and Whiting, D. (2010) The IDF Diabetes Atlas: Providing Evidence, Raising Awareness and Promoting Action. Diabetes Research and Clinical Practice, 87, 2-3. https://doi.org/10.1016/j.diabres.2009.11.006

[3] Chan, B.S., Tsang, M.W., Lee, V.W. and Lee, K.K. (2007) Cost of Type 2 Diabetes Mellitus in Hong Kong Chinese. International Journal of Clinical Pharmacology and Therapeutics, 45, 455-468. https://doi.org/10.5414/CPP45455

[4] Chatterji, S., Kowal, P., Mathers, C., Naidoo, N., Verdes, E., Smith, J.P., et al. (2008) The Health of Aging Populations in China and India. Health Affairs (Millwood), 27, 1052-1063. https://doi.org/10.1377/hlthaff.27.4.1052

[5] Cockram, C.S., Woo, J., Lau, E., Chan, J.C., Chan, A.Y., Lau, J., et al. (1993) The Prevalence of Diabetes Mellitus and Impaired Glucose Tolerance among Hong Kong Chinese Adults of Working Age. Diabetes Research and Clinical Practice, 21, 67-73. https://doi.org/10.1016/0168-8227(93)90099-Q

[6] Prince of Wales Hospital Charitable Foundation (2016) Health Feature-Diabetes Mellitus. http://www3.ha.org.hk/pwh/pwhcharity/dmpatient.htm\#knowledge

[7] Tsang, L.W.W. and Chan, N.N. (2012) Insulin Therapy: A Practical Approach. The Hong Kong Medical Diary, 17, 10-12.

[8] Huen, K.F., Low, L.C.K., Cheung, P.T., Wong, G.W.K., But, W.M., Kwan, E.Y.W., et al. (2009) An Update on the Epidemiology of Childhood Diabetes in Hong Kong. Hong Kong Journal of Paediatrics, 14, 252-259.

[9] The Diabetes Control and Complications (DCCT) Research Group (1995) Effect of Intensive Therapy on the Development and Progression of Diabetic Nephropathy in the Diabetes Control and Complications Trial. Kidney International, 47, 1703-1720. https://doi.org/10.1038/ki.1995.236

[10] Shichiri, M., Kishikawa, H., Ohkubo, Y. and Wake, N. (2000) Long-Term Results of the Kumamoto Study on Optimal Diabetes Control in Type 2 Diabetic Patients. Diabetes Care, 23(Suppl 2), B21-B29.

[11] Inzucchi, S.E., Bergenstal, R.M., Buse, J.B., Diamant, M., Ferrannini, E., Nauck, M., 
et al. (2015) Management of Hyperglycemia in Type 2 Diabetes, 2015: A Patient-Centered Approach Update to a Position Statement of the American Diabetes Association and the European Association for the Study of Diabetes. Diabetes Care, 38, 140-149. https://doi.org/10.2337/dc14-2441

[12] Maheux, P., Chen, Y.D., Polonsky, K.S. and Reaven, G.M. (1997) Evidence That Insulin Can Directly Inhibit Hepatic Glucose Production. Diabetologia, 40, 13001306. https://doi.org/10.1007/s001250050824

[13] Bazzano, L.A., Lee, L.J., Shi, L., Reynolds, K., Jackson, J.A. and Fonseca, V. (2008) Safety and Efficacy of Glargine Compared with NPH Insulin for the Treatment of Type 2 Diabetes: A Meta-Analysis of Randomized Controlled Trials. Diabetic Medicine, 25, 924-932. https://doi.org/10.1111/j.1464-5491.2008.02517.x

[14] Rosenstock, J., Davies, M., Home, P.D., Larsen, J., Koenen, C. and Schernthaner, G.A. (2008) Randomised, 52-Week, Treat-to-Target Trial Comparing Insulin Detemir with Insulin Glargine when Administered as Add-On to Glucose-Lowering Drugs in Insulin-Naive People with Type 2 Diabetes. Diabetologia, 51, 408-416. https://doi.org/10.1007/s00125-007-0911-x

[15] Swinnen, S.G., Simon, A.C., Holleman, F., Hoekstra, J.B. and Devries, J.H. (2011) Insulin Detemir versus Insulin Glargine for Type 2 Diabetes Mellitus. Cochrane Database of Systematic Reviews, 7, Article ID: CD006383. https://doi.org/10.1002/14651858.cd006383.pub2

[16] Cramer, J.A. and Pugh, M.J. (2005) The Influence of Insulin Use on Glycemic Control: How Well Do Adults Follow Prescriptions for Insulin? Diabetes Care, 28, 7883. https://doi.org/10.2337/diacare.28.1.78

[17] Lee, W.C., Balu, S., Cobden, D., Joshi, A.V. and Pashos, C.L. (2006) Medication Adherence and the Associated Health-Economic Impact among Patients with Type 2 Diabetes Mellitus Converting to Insulin Pen Therapy: An Analysis of Third-Party Managed Care Claims Data. Clinical Therapeutics, 28, 1712-1725. https://doi.org/10.1016/j.clinthera.2006.10.004

[18] Sharplin, P., Gordon, J., Peters, J.R., Tetlow, A.P., Longman, A.J. and McEwan, P. (2009) Improved Glycaemic Control by Switching from NPH to Glargine a Retrospective Observational Study. Cardiovascular Diabetology, 8, 3. https://doi.org/10.1186/1475-2840-8-3

[19] Sharplin, P., Gordon, J., Peters, J.R., Tetlow, A.P., Longman, A.J. and McEwan, P. (2009) Switching from Premixed Insulin to Glargine-Based Insulin Regimen Improves Glycaemic Control in Patients with Type 1 or Type 2 Diabetes. Cardiovascular Diabetology, 8, 9. https://doi.org/10.1186/1475-2840-8-9

[20] Currie, C.J., Poole, C.D., Tetlow, T., Holmes, P. and McEwan, P. (2007) The Outcome of Care in People with Type 1 and Type 2 Diabetes Following Switching to Treatment with either Insulin Glargine or Insulin Detemir in Routine General Practice in the UK: A Retrospective Database Analysis. Current Medical Research and Opinion, 23, S33-S39. https://doi.org/10.1185/030079907X167534

[21] Garg, S.K., Gottlieb, P.A., Hisatomi, M.E., D’Souza, A., Walker, A.J., Izuora, K.E., et al. (2004) Improved Glycemic Control without an Increase in Sever Hypoglycemic Episodes in Intensively Treated Patients with Type 1 Diabetes Receiving Morning, Evening, or Split Dose Insulin Glargine. Diabetes Research and Clinical Practice, 66, 49-56. https://doi.org/10.1016/j.diabres.2004.02.008

[22] Brown, J.B., Nichols, G.A. and Perry, A. (2004) The Burden of Treatment Failure in Type 2 Diabetes. Diabetes Care, 27, 1535-1540. https://doi.org/10.2337/diacare.27.7.1535

[23] Gabriely, I. and Shamoon, H. (2007) Awakening from Sleep and Hypoglycaemia in 
Type 1 Diabetes Mellitus. PLOS Medicine, 4, e99. https://doi.org/10.1371/journal.pmed.0040099

[24] Swinnen, S.G., Hoekstra, J.B. and De Vries, J.H. (2009) Insulin Therapy for Type 2 Diabetes. Diabetes Care, 32, S253-S259. https://doi.org/10.2337/dc09-s318

[25] Home, P. (2006) Global Guideline for Type 2 Diabetes: Recommendations for Standard, Comprehensive, and Minimal Care. Diabetic Medicine, 23, 579-593. https://doi.org/10.1111/j.1464-5491.2006.01918.x

[26] H.O.E. Study Investigators Group (2003) Safety and Efficacy of Insulin Glargine (HOE 901) versus NPH Insulin in Combination with Oral Treatment in Type 2 Diabetic Patients. Diabetic Medicine, 20, 545-551. https://doi.org/10.1046/j.1464-5491.2003.00999.x

[27] Chan, J.C., Gagliardino, J.J., Baik, S.H., Chantelot, J.M., Ferreira, S.R., Hancu, N., et al. (2009) Multifaceted Determinants for Achieving Glycemic Control: The International Diabetes Management Practice Study (IDMPS). Diabetes Care, 32, 227-233. https://doi.org/10.2337/dc08-0435

[28] Rosenstock, J., Schwartz, S.L., Clark, C.M., Jr. Park, G.D., Donley, D.W., et al. (2001) Basal Insulin Therapy in Type 2 Diabetes: 28-Week Comparison of Insulin Glargine (HOE 901) and NPH Insulin. Diabetes Care, 24, 631-636. https://doi.org/10.2337/diacare.24.4.631

[29] Tsai, S.T., Pathan, F., Ji, L., Yeung, V.T., Chadha, M., Suastika, K., et al. (2011) First Insulinization with Basal Insulin in Patients with Type 2 Diabetes in a Real-World Setting in Asia. Journal of Diabetes, 3, 208-216.

https://doi.org/10.1111/j.1753-0407.2011.00137.x

[30] Peyrot, M., Rubin, R.R., Lauritzen, T., Skovlund, S.E., Snoek, F.J., Matthews, D.R., et al. (2005) Resistance to Insulin Therapy among Patients and Providers: Results of the Cross-National Diabetes Attitudes, Wishes, and Needs (DAWN) Study. Diabetes Care, 28, 2673-2679.

[31] Davies, M.J., Gagliardino, J.J., Gray, L.J., Khunti, K., Mohan, V. and Hughes, R. (2013) Real-World Factors Affecting Adherence to Insulin Therapy in Patients with Type 1 or Type 2 Diabetes Mellitus: A Systematic Review. Diabetic Medicine, 30, 512-524. https://doi.org/10.1111/dme.12128

[32] Witthaus, E., Stewart, J. and Bradley, C. (2001) Treatment Satisfaction and Psychological Well-Being with Insulin Glargine Compared with NPH in Patients. Diabetic Medicine, 18, 619-625. https://doi.org/10.1046/j.1464-5491.2001.00529.x 
Submit or recommend next manuscript to SCIRP and we will provide best service for you:

Accepting pre-submission inquiries through Email, Facebook, LinkedIn, Twitter, etc. A wide selection of journals (inclusive of 9 subjects, more than 200 journals)

Providing 24-hour high-quality service

User-friendly online submission system

Fair and swift peer-review system

Efficient typesetting and proofreading procedure

Display of the result of downloads and visits, as well as the number of cited articles Maximum dissemination of your research work

Submit your manuscript at: http://papersubmission.scirp.org/

Or contact jdm@scirp.org 